\title{
HOW MODIFY THE CURRICULUM TO BENEFIT THE ACADEMICALLY TALENTED STUDENT?
}

Chairman: George D. Lange, Principal, M. S. Hershey Junior-Senior High School, Hershey, Pennsylvania

INTERROGATORS:

Robert V. Cogger, Principal, Memorial High School, Elmont, New York

Ernest A. Finney, Principal, Whittemore High School, Conway, South Carolina

Richard D. Van Pelt, Director of Secondary Education, College of Idaho, Caldwell, Idaho

\section{Summary of the presentation made by LESTER W. ANDERSON}

URING the past two to three years, the literature has been filled with suggestions that the secondary-school curriculum must "do something" for the academically talented student. Some high-school principals have "gotten on the band wagon" by launching various special provisions without always analyzing why such plans are necessary or what factors affecting curriculum are functioning with respect to this problem. It is the purpose of this discussion, therefore, to identify some of the current factors relating to curriculum development which have implications for educating the academically talented student.

1. Basic to curriculum development in a democracy is the desire by society to provide equal educational opportunity for all children. However, it is important that curriculum builders realize that equality of educational opportunity does not mean identical education for all youth. Rather, increasing efforts are being made in schools to implement the long established principle that the learning experiences should be different and unique, depending upon the peculiar abilities and interests of the individual pupil. Certainly there is nothing democratic about neglecting the specific needs of the academically talented child.

2. There is an increasing wave of concern for the "needs of society" as well as the "needs of youth." Since Sputnik I, there has been a dramatic realization that we cannot afford to waste brain power. It is apparent also that there is likely to be no oversupply of talent. It is imperative for the "needs of society," possibly even for national survival, that we conserve and develop our human resources to the maximum.

During the 1940's and 50's, schools were guided, to a great extent, by the objectives inherent in the statement of the Ten Imperative Needś of Youth. There is no intent here to suggest that such objectives, which emphasize the individual's needs, are no longer appropriate to guide

Lester W. Anderson is Associate Professor of Education, University of Michigan, Ann Arbor, Michigan. 
builders of curriculum. It is implied, however, that present conditions require greater sensitivity to "needs of society" parallel to the "needs of youth."

3. There has been a growing acceptance of the practice of grouping pupils according to ability, purpose and/or such other factors related to differentiation of instruction. The old cliche, "grouping is undemocratic," no longer dictates instructional practices.

4. There appears to be an increasing commitment to district reorganization. Such activity, plus the rapid increase in relatively large suburban high schools, is resulting in secondary schools of sufficient size to provide greater diversity of offerings, better services to students, and greater experimentation in meeting the needs of academically talented students.

5. Financial support provided in the National Defense Education Act is making it possible to upgrade guidance and counseling services considerably in our high schools. As both the quality and quantity of guidance and counseling services are improved, there should be more intelligent and skillful adaptations made in the curriculum based on the specific needs of individuals, including the needs of academically talented students.

6. Psychologically, it has become much more acceptable for a highschool student to be a "brain." Special programs such as the recently developed (1955) National Merit Scholarship Program, the Advanced Placement Program, the North Central Association's Project for the Motivation of Superior and Talented Students, the expanded use of examinations for admission to college, and other similar programs have helped in focusing attention on the desirability of recognizing academic achievement as a desirable goal. Although there are some hazards in terms of curriculum development based on special testing programs, it must be recognized that these programs have affected the psychological atmosphere of the high school, because all such programs have as a major objective the elevation of scholarship and the recognition that high scholastic achievement is an attribute worth developing.

No doubt there are other factors and conditions which could be identified as making a major contribution in the area of modifying the curriculum to benefit the academically talented student. This discussion is not intended as an all-inclusive listing of these developments. However, the above factors do support the general conclusion that the conditions of the times demand a curriculum which provides maximum opportunity for academically talented students. High-school principals must be aware of these developments and provide adequate leadership to their faculties in developing appropriate curriculum content and practices for the education of this group of students. 


\section{Summary of the presentation made by J. E. FERGASON}

\section{$\mathrm{O}$}

UR founding fathers, it may be assumed, never intended the Declaration of Independence to read that all men are created intellectually equal, and yet the massive structure of public education appears built on just that appalling error of thought. The inferior student suffers more severely than the gifted one from this mixing in a kind of intellectual melting pot. The gifted student is stifled and bored, but the slow learner is likely to be forced into retreat from life by the cruelty of impossible competition. Therefore, as educators we must devise some method to teach, in our schools, both the gifted and the inferior. This writer believes that the curriculum must be modified tremendously for the gifted pupils.

Provisions for the discovery of the gifted and talented youth must be accomplished early in junior high school. Then plans for their maximum development should be carried forth in the curriculum planning. To accomplish these things, special programs must be adopted. Differentiation of materials and methods of instruction should follow; otherwise, grouping of any kind is useless. It should be noted here that there is no special motivation built into a gifted class. Motivation and purpose still are developed by good teaching.

We modify our curriculum requirements to the extent that we permit a pupil to take five solids and physical education in the first year of high school. Pupils are grouped in foreign language, algebra, and English.

Talented youth are also identified and grouped in our seventh and eighth grades. However, this is more difficult in these grades as we run a schedule of block programs. Generally, pupils are together most of the day in these blocks. We identify these special gifted rooms as "Experimental Groups."

The author has had the good fortune of having discovered a method of teaching some gifted pupils in a "Special Experimental Class." Eight highly talented pupils were chosen from each of the three grades in our school. These pupils have been making their own curriculum to the extent that they are choosing the subjects to be studied. This "Special Class" meets once or twice a week. The pupils are drawn from their regular classes to participate in this program. All of the work missed must be made up with the teacher of their regular classes. We have not had sufficient funds to pay people to come to our school to teach this "Special Class"; therefore, we have been scheduling "volunteer" people from our city. Fortunately we can draw on people to teach journalism, French, German, and citizenship, to name a few of the areas. We are getting outstanding recognition in our community on this project.

We have modified our curriculum recently to include biology, speech, algebra also in our ninth grade. General Science and Algebra I are to

J. E. Fergason is Principal of David Crockett Junior High School, 4720 Floyd Avenue, Amarillo, Texas. Enrollment, 790. 
be given in the eighth grade. The aformentioned practices are very common in the junior high schools in this area.

In summary it may be said that: (1) the first problem to be solved in directing our attention to the gifted student is to identify properly or discover him and (2) the second problem is that of providing an enriched educational curriculum for him. The author believes that an enriched curriculum is the answer over an accelerated curriculum.

\section{Summary of the presentation made by STEWART B. ATKINSON}

Tr.

HE subject matter of this paper consists of a description of how the curriculum of one senior high school has been modified to benefit (it hopes) its academically talented students. Darien High School is a public high school, thirty-seven miles from New York City. The majority of the graduates of the high school enter some sort of post-high-school educational institutions $(70 \%$ college, $10 \%$ other educational institutions).

The curriculum adjustments made in this high school with the academically talented student in mind are described as follows:

\section{Mathematics}

Prior to 1955 the program in mathematics was as follows: grade 10 , Algebra II; grade 11, Plane Geometry; and grade 12, Solid Geometry $(1 / 2)$ and Trigonometry (1/2). On the assumption that the brightest students were wasting considerable time under this program and were, in addition, not going far enough in the field of mathematics for the advanced sections, we cut in half the time assigned to all senior highschool courses in mathematics, and eventually added calculus in grade 12. The new program in mathematics for the bright students became: grade 9 (JHS) for Algebra I; grade 10, Intermediate Algebra for one-half year and Plane Geometry for one-half year; grade 11, Solid Geometry and Trigonometry one-fourth year each and Probability and Statistics for one-half year; and grade 12, Calculus.

After two years of this program, there develuped a feeling on the part of teachers that the enrichment lost in such an accelerated program should be rescued, and so another revision was made possible by scheduling Algebra $I$ in grade 8 for the bright. As a result of this change, we now have the following program in mathematics for the best students in this subject: grade 8 , Algebra I; grade 9 , Algebra II; grade 10, geometry (Plane including Solid); grade 11, Trigonometry and Advanced Algebra; and grade 12, Analytic Geometry and Calculus. This grade 12 offering is an advanced placement course.

Stewart B. Atkinson is Principal of Darien High School, Darien, Connecticut. Enrollment, 825. 


\section{SCIENCE}

Science is another field in which there have been, in our school, several curriculum changes aimed at benefitting the academically talented student. Our original science offerings were the following: grade 9 (JHS), general science; grade 10, biology; grade 11, chemistry; and grade 12, physics. In addition to a general stiffening of the work of all top sections, we now offer biology in grade 9 to selected students. This makes the following science schedule possible: grade 9, biology; grade 10, chemistry; grade 11, physics; and grade 12, Biology II or Chemistry II or Physics II. In addition to adding more courses for the bright science student, the general approach to one course has been changed. This is in physics, where the PSSC approach is used in the first section.

\section{Foreign Languages}

No courses have been added recently to the offerings in the foreign language field. The sole curriculum adjustment here for the bright student has been the following out in French IV of the recommendations of the Advanced Placement Program. These call for a severe toughening of the work of the course, in the case of the regular French IV offering of most high schools.

\section{ENGLISH}

In a school where homogeneous grouping starts with the English classes, and in which such classes are grouped on as many levels as there are sections (twelve different sections in English IV), it may be properly supposed that the top class is very highly selected and is composed of very bright young people. In our school this situation exists to the degree that the first section of English IV is an advanced placement course because of the very nature of its regular class activities.

\section{Social Studies}

Two curriculum adjustments have been made recently in the field of the social studies, both in behalf of the bright students. (1) The first section of United States history is now an advanced placement class. (2) We are adding to the social studies program in grade 12 a course in Asia Studies to be taken in addition to the regular course, C.S.I., by interested students who have achieved well in previous World history and U.S. history. 